\title{
Anxiety, depression, and quality of life in mothers of newborns with microcephaly and presumed congenital Zika virus infection
}

\author{
Sheila Jaqueline Gomes dos Santos Oliveira ${ }^{1}$ - Emanuela Santos de Melo $^{2}$ • \\ Daniele Machado Reinheimer ${ }^{1}$. Ricardo Queiroz Gurgel ${ }^{1}$ - Victor Santana Santos ${ }^{1}$. \\ Paulo Ricardo Saquete Martins-Filho ${ }^{1,3}$
}

Received: 18 July 2016 / Accepted: 10 August 2016/Published online: 18 August 2016

(C) Springer-Verlag Wien 2016

\section{Dear Editor,}

In Brazil, an unusual increase of newborns with microcephaly has been reported since August 2015 (França et al. 2016), with a strong evidence of association with congenital Zika virus (ZIKV) infection (Martines et al. 2016). In February 2016, the World Health Organization declared the clusters of microcephaly and other neonatal malformations reported in Brazil a Public Health Emergency of International Concern (WHO 2016). In June 2016, the Brazilian Ministry of Health confirmed 1410 cases of microcephaly in the Northeast region, out of which $111(7.9 \%)$ cases in the Sergipe state, the smallest state of the Brazilian Federation, with $\sim 2$ million population (BRAZIL 2016).

Studies have shown an increased risk of microcephaly when mothers are infected with ZIKV during the first trimester of pregnancy (Cauchemez et al. 2016; Johansson et al. 2016). Unfortunately, there is currently no vaccine or medication to prevent ZIKV infection, which may be asymptomatic in an estimate of $80 \%$ of cases (Duffy et al. 2009). Recently, in Colombia, four infants with microcephaly had laboratory evidence of congenital ZIKV whose mothers had asymptomatic infection during pregnancy (Pacheco et al. 2016). Because of growing evidence,

Paulo Ricardo Saquete Martins-Filho martins-filho@ufs.br

\section{Federal University of Sergipe, Aracaju, Sergipe, Brazil}

2 Tiradentes University, Aracaju, Sergipe, Brazil

3 Universidade Federal de Sergipe, Hospital Universitário, Laboratório de Patologia Investigativa, Rua Cláudio Batista, s/n. Bairro Sanatório, Aracaju, Sergipe CEP: 49060-100, Brazil experts have suggested safety measures to avoid ZIKV infection during pregnancy, especially in areas where the virus has been circulating.

Brazilian newborns with microcephaly have demonstrated severe abnormalities in the central nervous system including brain dysgenesis and intracranial calcifications consistent with an intrauterine infection (Microcephaly Epidemic Research Group 2016). The expectancy of microcephaly diagnosis may lead to higher levels of parental stress because of the uncertainty regarding the developmental outcome of their children. To the best of our knowledge, there have been no previous studies evaluation anxiety, depression, and quality of life in mothers of newborns with microcephaly and presumed congenital ZIKV infection. We evaluated nine consecutive mothers of babies with microcephaly born in a public maternity in Sergipe state, Brazil, from November 2015 to June 2016. The newborns with microcephaly presented typical alterations indicating congenital infection including intracranial calcifications, cerebral ventricles dilation, or changes in the posterior fossa and other clinical signs found by any image diagnostic method or ZIKV identification in laboratory tests (BRAZIL 2016). We compared data regarding anxiety, depression, and quality of life with those from a concurrent control group of 20 mothers of healthy newborns. Psychometric evaluation of anxiety and depression was performed using the State-Trait Anxiety Inventory and the Beck Depression Inventory, respectively. Quality of life was assessed using the World Health Organization Questionnaire - short version (WHOQOL-BREF). Differences between the groups were compared using the Mann-Whitney test with a significance level of $5 \%$. All participants signed the informed consent. Data were collected during the first $24 \mathrm{~h}$ after birth.

The mothers' age of newborns with microcephaly ranged from 18 to 39 years. Only three mothers were married and all 
Fig. 1 a Psychometric evaluation and $\mathbf{b}$ quality of life in mothers of newborns with microcephaly compared to mothers of healthy babies

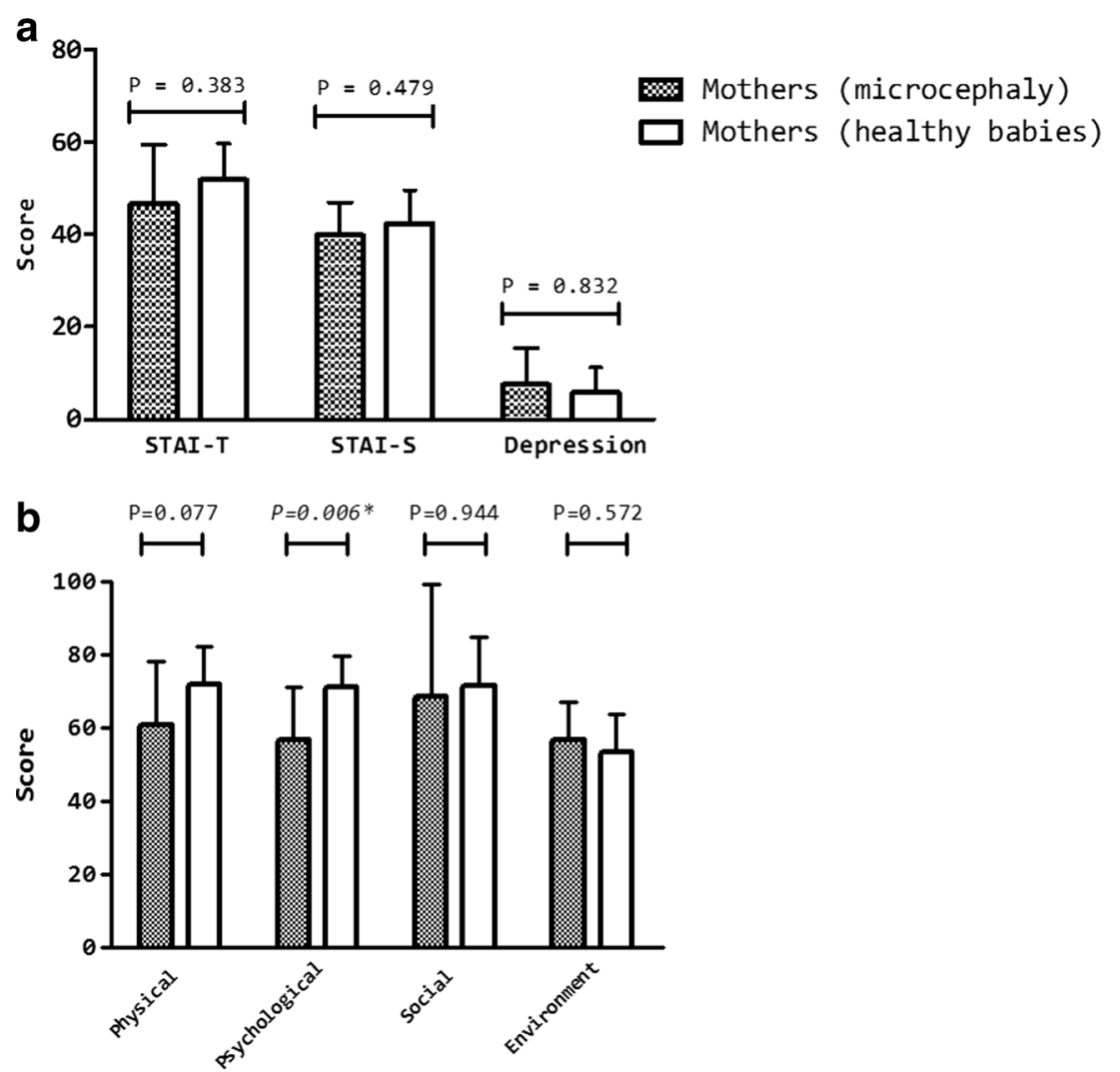

of them had low income. In the control group, the age ranged from 19 to 35 years and most of them had low income (80\%). Most mothers reported to live in rural areas. We found high levels of anxiety (scores >39) in both groups, without statistical difference between them. In both groups, depression scored as normal (0-9) (Fig. 1a). Mothers of newborns diagnosed with microcephaly had significantly lower scores on psychological domain of WHOQOL-BREF compared to healthy babies' mothers $(P=0.006)$. Psychical, social, and environment domains were not different between groups (Fig. 1b).

In this report, we found that ZIKV-related microcephaly is a factor significantly associated with high levels of anxiety and low scores in psychological domain during the first $24 \mathrm{~h}$ after birth. The psychological domain includes questions of positive and negative feelings, self-esteem, body image and physical appearance, personal beliefs, and attention. Fear has struck Brazilian maternity since ZIKV was linked to the brain damage in newborns. As most ZIKV cases may cause no noticeable symptoms, women have no idea if they were infected during pregnancy, which may lead to increased levels of anxiety and/or psychological distress. In addition, the fear of stigmatization of microcephaly may negatively affect the parents' emotional and social functioning after birth.

Healthcare providers must be prepared to receive mothers and newborns with microcephaly and should be aware of the latest guidelines on assessment and management of ZIKV and its potential consequences (Burke et al. 2016). Psychosocial intervention programs can make a significant contribution to the short-term maternal mental health including anxiety, depression, and self-esteem (Barlow and Coren 2004). Our study highlights the importance of multidisciplinary counseling and the need to identify psychoeducational strategies for promoting quality of life in mothers of newborns with microcephaly associated with presumed ZIKV congenital infection. Our results are limited to in-hospital outcomes. Future investigations are necessary to evaluate anxiety, depression, and quality of life in a long-term follow-up.

\section{Compliance with ethical standards}

Conflict of interest The authors declare that they have no conflict of interest.

\section{References}

Barlow J, Coren E (2004) Parent-training programmes for improving maternal psychosocial health. Cochrane Database Syst Rev :CD002020. doi:10.1002/14651858.CD002020.pub2

BRAZIL (2016) Ministerio da Saude, Brazil. Informe Epidemiológico $N^{\circ}$ 31-Semana Epidemiológica (SE) 24/2016 (12 a 18/06/2016) Monitoramento Dos Casos De Microcefalia No Brasil.

Burke RM, Pandya P, Nastouli E, Gothard P (2016) Zika virus infection during pregnancy: what, where, and why? Br J Gen Pract 66:122123. doi:10.3399/bjgp16X683917 
Cauchemez S, Besnard M, Bompard P et al (2016) Association between Zika virus and microcephaly in French Polynesia, 2013-15: a retrospective study. Lancet 387:2125-2132. doi:10.1016/S0140-6736(16)00651-6

Duffy MR, Chen T-H, Hancock WT et al (2009) Zika Virus Outbreak on Yap Island, Federated States of Micronesia. N Engl J Med 360: 2536-2543. doi:10.1056/NEJMoa0805715

França GVA, Schuler-faccini L, Oliveira WK et al (2016) Congenital Zika virus syndrome in Brazil: a case series of the first 1501 livebirths with complete investigation. Lancet 6736:1-7. doi:10.1016/S0140-6736(16)30902-3

Johansson MA, Mier-Y-Teran-Romero L, Reefhuis J et al (2016) Zika and the Risk of Microcephaly. N Engl J Med:1-4. doi:10.1056 /NEJMp1605367
Martines RB, Bhatnagar J, de Oliveira Ramos AM et al (2016) Pathology of congenital Zika syndrome in Brazil: a case series. Lancet 6736:17. doi:10.1016/S0140-6736(16)30883-2

Microcephaly Epidemic Research Group (2016) Microcephaly in Infants, Pernambuco State, Brazil, 2015. Emerg Infect Dis 22:1090-1093. doi:10.3201/eid2206.160062

Pacheco O, Beltrán M, Nelson CA (2016) Zika Virus Disease in Colombia Preliminary Report. N Engl J Med:1-10. doi:10.1056 NEJMoa1604037

WHO (2016) WHO Director-General summarizes the outcome of the Emergency Committee regarding clusters of microcephaly and Guillain-Barré syndrome. Geneva. 